\title{
The PCR detection and phylogenetic characterization of Babesia microti in questing ticks in Mongolia
}

Bumduuren Tuvshintulga ${ }^{\text {ab }}$, Thillaiampalam Sivakumara, Badgar Battsetseg, Sandag-ochir Narantsatsaral $^{\mathrm{b}}$, Batsaikhan Enkhtaivan ${ }^{\mathrm{b}}$, Banzra gch Battur $^{\mathrm{b}}$, Kyoko Hayashida $^{\mathrm{a}}$, Kazuhiro Okubo $^{\mathrm{a}}$, Takahiro Ishizaki ${ }^{\mathrm{a}}$, Noboru Inoue ${ }^{\mathrm{a}}$, Ikuo Igarashi ${ }^{\mathrm{a}}$, and Naoaki Yokoyama ${ }^{\mathrm{a}}$ *

${ }^{a}$ National Research Center for Protozoan Diseases, Obihiro University of Agriculture and Veterinary Medicine, Inada-cho, Obihiro, Hokkaido 080-8555, Japan

${ }^{b}$ Laboratory of Molecular Genetics, Institute of Veterinary Medicine, Mongolian State University of Agriculture, Ulaanbaatar, Mongolia

*Corresponding author: Naoaki Yokoyama

National Research Center for Protozoan Diseases, Obihiro University of Agriculture and Veterinary Medicine, Inada-cho, Obihiro, Hokkaido 080-8555, Japan

Tel: +81-155-49-5649; Fax: +81-155-49-5643; E-mail: yokoyama@obihiro.ac.jp 


\section{ABSTRACT}

Babesia microti is a tick-transmitted zoonotic hemoprotozoan parasite. In the present study, we investigated B. microti infection in questing ticks in Mongolia. A total of 219 questing ticks were collected from three different Mongolian provinces (Bayan-Olgii, Khovsgol, and Selenge). Of these, 63 from Selenge were identified as Ixodes persulcatus, while the remaining 156 (from all three provinces) were identified as Dermacentor nuttalli. When the tick DNA samples were screened using a B. microti-specific nested PCR, 19 (30.2\%) of the $63 \mathrm{I}$. persulcatus ticks were found to be B. microti-positive. The parasite was not detected in D. nuttalli. Subsequently, the $18 S$ rRNA, cox1, and tufA sequences of $B$. microti were amplified, sequenced, and subjected to phylogenetic analyses. Sequencing analyses showed that the Mongolian 18S rRNA, cox1, and tufA sequences were 99.6-100\%, 96.7-97.2\%, and 94.7-95.3\% homologous, respectively, with B. microti R1 strain US-type sequences from humans. In the phylogenetic analyses, the Mongolian cox 1 and tufA sequences were found to be separate lineages, which formed sister-clades to the R1 strain sequences, while all of the Mongolian B. microti $18 S$ rRNA sequences were clustered within US-type clade containing several other sequences of human origin. In conclusion, in addition to reporting the presence of $B$. microti for the first time in questing ticks in Mongolia, the present study found that Mongolian $I$. persulcatus ticks were infected with US-type $B$. microti. These findings warrant large-scale studies to detect and characterize $B$. microti in ticks, small mammals, and humans. Such studies should provide us with a better understanding of zoonotic Babesia epidemiology in Mongolia.

Keywords: B. microti, cox1, Mongolia, Ticks, tufA, $18 S$ rRNA 


\section{Introduction}

Human babesiosis is a tick-transmitted zoonotic protozoan disease caused by several Babesia species, including Babesia microti, B. divergens, B. duncani, Babesia sp "venatorum" (EU1), and Babesia sp. KO1 [1-6]. Clinically, human babesiosis is characterized by a malaria-like illness, and the clinical manifestations may include fever, headache, myalgia, severe anemia, respiratory failure, and death [7]. Outside of North America, where human cases of $B$. microti infection are commonly found, human infections have been reported in Europe, Asia, and Australia [8-13]. The B. microti lifecycle involves tick vectors and their vertebrate hosts [4]. Vertebrates, including humans, are infected with $B$. microti through the bites of infected ticks. Although humans are a dead-end host for $B$. microti, people with asymptomatic infections can transmit the parasite to uninfected people through blood donations [14-16]. The transplacental and perinatal transmission of B. microti has also been reported in humans [17].

For the control of tick-borne pathogens, tick control methodologies must be employed $[18,19]$. The first step toward effective tick control begins with the identification of the species of ticks that transmit $B$. microti, because the risk of contracting human babesiosis caused by B. microti is associated with the distribution of its tick vectors [20]. In the last few decades, studies have investigated the prevalence of $B$. microti in ticks distributed in different geographical regions of the world. The parasite has been detected in several tick species, including Ixodes scapularis [21], I. ricinus [22], I. persulcatus [23], and I. ovatus [24]. B. microti parasites in ticks are usually detected by a PCR, after which DNA sequencing and phylogenetic analyses are used for confirmation [24,25]. In the recent past, in addition to the commonly used $18 \mathrm{~S}$ ribos omal RNA sequences (18S rRNA), the genes encoding $\beta$-tubulin and chaperonin-containing t-complex polypeptide 1 (CCT7) have been used for the genetic 
characterization of $B$. microti isolates $[26,27]$. Similarly to other apicomplexan parasites, $B$. microti contains three separate genomes: nuclear, mitochondrial, and plastid [28-30]. In addition to genes in the nuclear genome (e.g., $18 S$ rRNA), mitochondrial genes (e.g., cytochrome c oxidase subunit 1, cox1) and plastid genes (e.g., the apicoplast translation elongation factor tuA gene, tufA) have also been widely used for evolutionary studies on the plastid-containing organisms [31-34].

Several Babesia parasites have been reported in Mongolia [35-37], a land-locked country located between Russia and China. Both of these bordering countries have reported the presence of $B$. microti in ticks and humans in their territories [12,23]. A recent study detected B. microti infections among Mongolian farmers, using PCR and serological methods [38]. However, the parasite infection in ticks is yet to be studied in this country. Thus, in the present study, we screened DNA samples from questing ticks collected in Mongolia for the presence of $B$. microti. Subsequently, we analyzed the $18 S$ rRNA, cox1, and tufA sequences amplified from the B. microti-positive DNA samples to confirm our findings. 


\section{Mate rials and methods}

\subsection{Tick and DNA samples}

Questing ticks were collected in the mountain areas of Bayan-Olgii (westernmost) province and in the forest areas of Khovsgol (northernmost) and Selenge (northern) provinces of Mongolia in 2012 and 2013 by a flagging method. The collected ticks were morphologically identified as described previously $[39,40]$. After morphological identification, the collected ticks were subjected to DNA extraction. Briefly, individual ticks were cut into small pieces using sterile surgical blades, digested with a lysis buffer (20 mM Tris-HCl pH 8.0, 1 mM EDTA pH 7.5, 10 mM NaCl, 1\% SDS, and 100 g/ml Proteinase K), and then purified by a phenol/chloroform method. After ethanol precipitation, the DNA samples were dissolved in $50 \mu \mathrm{l}$ of double distilled water (DDW), and then stored at $-30^{\circ} \mathrm{C}$ until further use.

\subsection{PCR detection of B. microti}

All of the DNA samples were screened for the presence of $B$. microti using a previously described B. microti-specific nested PCR (Table 1) [41]. After gel electrophores is and ethidium bromide staining, the PCR products were identified under UV light. A Blood DNA sample sourced from a mouse experimentally infected with B. microti (Munich strain) was used as a positive control for the PCR. In addition to using several negative controls, filtered tips and designated pipette sets for pre- and post-PCR handling were used for all of the PCR procedures described in this article to avoid possible contamination.

\subsection{PCR amplification of 18S rRNA, cox1 and tufA}


B. microti-positive tick DNA samples were subjected to three separate PCR processes for the $18 S$ rRNA, cox1, and tufA genes. A nested PCR employing the previously described primer sets was used to amplify $18 S$ rRNA [42], while single step PCRs using the primers designed in the present study were used to amplify the cox 1 and tufA genes (Table 1). For the first round of $18 S$ rRNA amplification, $1 \mu$ of tick DNA was added into $9 \mu$ of the PCR reaction mixture containing $1 \mu \mathrm{l}$ of $10 \times$ PCR buffer (Applied Biosystems, Branchburg, NJ, USA), $1 \mu \mathrm{l}$ of $2 \mathrm{mM}$ dNTPs (Applied Biosystems), $0.2 \mu \mathrm{l}$ of $10 \mu \mathrm{M}$ Piro0F2 and Piro6R2 primers (Table 1), $0.1 \mu \mathrm{l}$ of $5 \mathrm{U} / \mu \mathrm{l}$ Taq DNA polymerase (AmpliTaq Gold; Applied Biosystems), and $6.5 \mu \mathrm{l}$ of DDW. For the $\operatorname{cox} 1$ and tufA genes, the $9 \mu \mathrm{l}$ reaction mixture included $5 \mu$ l of $2 \times$ Ampdirect®plus PCR buffer (Shimadzu Corporation, Kyoto, Japan), 0.2 $\mu \mathrm{l}$ of $10 \mu \mathrm{M}$ primers (Cox1F133 and Cox1R1130, and EFtuAF2 and EFtuAR2, respectively), $0.1 \mu \mathrm{l}$ of $5 \mathrm{U} / \mu \mathrm{l}$ Taq DNA polymerase (ExTaq; Takara BIO INC, Shiga, Japan), and $3.5 \mu \mathrm{l}$ of DDW. Finally, $1 \mu \mathrm{l}$ of tick DNA was added to each reaction mixture before the PCR amplification. The initial enzyme activation step at $95^{\circ} \mathrm{C}$ for 5 min was followed by 40 (18S rRNA) or 45 (cox1 and tufA) cycles, each containing a denaturing step at $94^{\circ} \mathrm{C}$ for $1 \mathrm{~min}$, an annealing step at the relevant temperatures shown in Table 1 for $1 \mathrm{~min}$, and an elongation step at $72^{\circ} \mathrm{C}$ for $90 \mathrm{~s}$. After the final elongation step at $72^{\circ} \mathrm{C}$ for $10 \mathrm{~min}$, the $\operatorname{cox} 1$ and tufA PCR products were analyzed by gel electrophoresis. For $18 S \mathrm{rRNA}$, the PCR products $(1 \mu \mathrm{l})$ were transferred to new tubes containing reaction mixtures with compositions that were similar to those used for the first amplification round, with the exception that the primers were replaced with Piro1F2 and Piro5R2, before being subjected to cycling conditions that were similar to those of the first round.

\subsection{DNA cloning and sequencing}


The 18S rRNA, cox1, and tufA amplic ons were cloned and sequenced, using previously described methods with minor modifications [43]. Briefly, after gel electrophores is, PCR amplic ons were purified using a NucleoSpin® Gel and PCR Clean-up Kit (MACHEREY-NAGEL, Düren, Germany), ligated to a PCR 2.1 plasmid vector (TOPO, Invitrogen, Carlsbad, CA, USA), transformed into Escherichia coli cells (TOP 10, Invitrogen), and then plated onto Luria-Bertani agar plates (Invitrogen). Three clones were picked for each PCR amplicon and then subjected to DNA sequencing, us ing an ABI PRISM 3100 genetic analyzer (Applied Biosystems).

\subsection{Sequence and phylogenetic analyses}

The $18 S$ rRNA, cox1, and tufA DNA sequences were initially analyzed by the basic local alignment search tool (BLAST) (http://blast.ncbi.nlm.nih.gov/Blast.cgi), and then analyzed by MatGAT 2.02 software [44] to calculate their identity scores. Subsequently, three separate phylogenetic trees were constructed for the $18 S$ rRNA, cox1, and tufA sequences, using the sequences that were generated in the present study and the homologous gene sequences that are available in GenBank. An MEGA software version 6.06 [45] was used to construct maximum likelihood phylogenetic trees, based on Tamura 3-parameter (18S rRNA) [46] or General Time Reversible (cox1 and tufA) substitution models [47]. 


\section{Results}

A total of 219 questing tic ks were collected from three different Mongolian provinces. Out of the 219 ticks, 102, 16, and 101 were collected from the Bayan-Olgii, Khovsgol, and Selenge provinces, respectively. All of the ticks collected from the Bayan-Olgii and Khovsgol provinces were identified as Dermacentor nuttalli, while 63 I. persulcatus and 38 D. nuttalli were identified from Selenge. A B. microti-specific nested PCR assay detected the parasite DNA in 19 of the tick DNA samples. All of the B. microti-positive DNA samples were sourced from I. persulcatus, indicating that the parasite-positive rate was $30.2 \%$ among this tick species, whereas none of the DNA derived from $D$. nuttalli was positive for this species of parasite.

When all of the $B$. microti-positive DNA samples were subjected to three separate PCR processes (which targeted the $18 S$ rRNA, cox1, and tufA genes [Table 1]), these gene sequences were amplified in 9, 16, and 13 DNA samples, respectively. The differences in the sensitivities of the individual PCR processes, based on the amplicon size and the copy numbers of the target genes, might expla in these discrepancies. Sequencing analyses showed that the sizes of the amplified $18 S$ rRNA, cox1, and tufA fragments were 1,667-1,668, 1,023, and 823 bp, respectively. For each PCR amplicon, three clones were sequenced, and the analyses showed that the sequences often varied among the clones. As a result, 21 (LC005752-LC005772), 36 (LC005778-LC005813), and 23 (LC005814-LC005836) of the $18 S$ rRNA, cox1, and tufA sequences, respectively, were registered with GenBank. The identity scores among the $18 S$ rRNA, cox1, and tufA nucleotide sequences were $99.3-100 \%$, 98.6-99.9\%, respectively. Moreover, the similarities among the cox1 and tufA amino acid sequences were $97.4-100 \%$ and $96.7-100 \%$, respectively. Additionally, the $18 S$ rRNA sequences were highly homologous (99.6-100\%) with the $18 S r R N A$ sequences from the $B$. 
microti R1 strain (FO082874). Similarly, cox1 and tufA nucleotide sequences were 96.797.2\% and 94.7-95.3\% homologous, respectively, with those from the R1 strain (FO082868 and LK028575). In addition, the cox1 and tufA amino acid sequences shared $98.5-100 \%$ and 93.5-95.3\% similarities, respectively, with the R1 strain sequences.

Three separate phylogenetic trees were constructed using the $18 S$ rRNA, cox1, and tufA sequences, together with the homologous sequences that were retrieved from GenBank. In the phylogenetic tree based on the $18 \mathrm{~S} r R N A$ sequences, all of the Mongolian sequences were clustered within the US-type clade (Fig. 1). This clade contains sequences from several other countries, including Zaire (AB190459), the United States (AF231348), Japan (AB190435), and Germany (EF413181). For the cox1 and tufA genes, only the sequences from the R1 and Munich strains were available in GenBank; hence these, together with the Mongolian sequences, were used for phylogenetic construction (Fig. 2 and Fig. S1). In both of the cox1- and tufA-based phylogenetic trees, the Mongolian sequences were identified as separate lineages, which formed sister-clades to the R1 strain sequences within the major clades of B. microti. 


\section{Dis cussion}

Babesia microti, which is primarily transmitted by biting ticks, causes human babesiosis. Babesiosis caused by $B$. microti has also been reported among travelers in endemic areas $[48,49]$. Hence, effective strategies to control the tick vectors of babesiosis are of paramount importance. In the present study, we investigated questing ticks in Mongolia to determine the prevalence of $B$. microti in these insects. The ticks collected from three provinces included $D$. nuttalli, which is the most abundant tick species in Mongolia. The $I$. persulcatus species, which was previously reported in the Khovsgol and Selenge provinces [50], was not detected in Khovsgol in the present study. The low number of samples from Khovsgol might explain this discrepancy. The presence of B. microti-DNA was only detected from I. persulcatus. In agreement with the present findings, the parasite has also been identified in I. persulcatus in previous studies in Russia and China; both countries neighbor Mongolia [23,51].

Babesia microti refers to a group of closely related subpopulations, which are usually classified by the analys is of their $18 S$ rRNA sequences [52,53]. Based on the phylogeny of the $18 S$ rRNA sequences of $B$. microti, the parasite population can be divided into four major types: Munich, Kobe, U.S. (US-type), and Hobetsu types [52]. The phylogeny constructed in the present study revealed that all of the Mongolian 18S rRNA sequences corresponded to the US-type. In addition, the Mongolian $18 S$ rRNA sequences shared high identity scores with the sequence from $B$. microti R1 strain, which is a well-studied US-type human isolate [28-30]. These findings suggest that the parasites detected in the present study might be infective to humans. However, this assumption is not conclusive at this point, as the US-type also includes sequences sourced from other host animals in addition to those that are sourced from humans. Furthermore, in a laboratory-based investigation, a US-type B. microti isolate was 
successfully transmitted by the I. persulcatus to hamsters [24]. Therefore, the detection of the US-type in I. persulcatus suggests that this tick species might be a vector of $B$. microti in Mongolia. Babesia microti was very recently detected in a human blood sample from Khutul city in Selenge province, Mongolia by molecular and serological tests [38]. The authors found that the 18S rRNA sequences were similar to either Chinese (KF410827) or Russian (AY144693) B. microti sequences. The Chinese sequence (KF410827) can be class if ied as the Kobe-type according to the phylogenetic trees that were constructed in the present study (Fig. 1); however, the Russian sequence (AY144693) was not considered, as the length of this sequence $(1,254 \mathrm{bp})$ was relatively shorter than the sequences that we analyzed in the present study. At this point, we are not able to conclude that the $B$. microti detected in humans in Mongolia can be classified as the Kobe-type, as these recently determined Mongolian sequences are not available in a public database.

In addition to $18 S$ rRNA, mitochondrial, and plastid gene sequences have been extensively used in evolutionary studies [31-34,54-56]. Hence, in the present investigation, we used the cox1 (mitochondrial gene) and tufA (plastid gene) to characterize the B. microti species that we detected in ticks. All of the Mongolian sequences clustered together in the respective phylogenetic trees, and formed sister-clades to those of the R1 strain sequences. The common ancestors of the Mongolian and R1 strain sequences appeared as sister-clades to the cox 1 and tufA sequences from the Munich strain. These observations indicate that the cox 1 and tufA sequences in the present study are from B. microti. Mitochondrial genes are known to evolve rapidly in comparis on to nuclear genes [54]. Thus, the cox1-based phylogeny may have divided the sequences into more distinct clades than those of the nuclear gene-based phylogenetic trees. This might explain why the cox1 sequences from the R1 and Mongolia strains were clearly separated in the phylogeny, despite the fact that their $18 S$ rRNA sequences were found in a monophyletic clade. In addition, the conserved nature of $\operatorname{cox} 1$ among the four 
distinct mitochondrial genomes of B. microti, [32], makes it an excellent target for PCR amplification. The present study also infers that the tufA-based phylogeny separates the $B$. microti sequences, similar to the cox1 phylogeny. These findings collectively suggest that both cox 1 and tufA are useful targets for the phylogenetic characterization of $B$. microti. However, large numbers of gene sequences from different geographical regions should be analyzed to confirm this assumption.

In summary, the analysis of questing ticks in Mongolia found that $I$. persulcatus ticks are infected with $B$. microti, and that the detected parasites can be classified as B. microti UStype, based on the $18 S$ rRNA sequences. The results further suggest that cox 1 and tufA are potentially useful markers for phylogenetic characterization of B. microti. Having identified B. microti in Mongolian ticks, our findings warrant large-scale surveys to detect and characterize B. microti in small mammals, ticks, and humans. Surveys of this type would provide a more comprehensive understanding of the epidemiology of this zoonotic parasite in Mongolia.

Supplementary data

Supplementary Fig. S1

\section{Acknowledgments}

We thank the Mongolian veterinarians who were involved in the insect sampling. This study was supported by grants from JST/JICA, Science and Technology Research Partnership for Sustainable Development (SATREPS), the Ministry of Education, Culture, Sport, Science, and Technology, Japan (MEXT) and from Research on Regulatory Science of 
Pharmaceuticals and Medical Devices of Ministry of Health, Labour and Welfare in Japan (H26-iyaku-ippan-002). 


\section{References}

[1] Eskow ES, Krause PJ, Spielman A, Freeman K, Aslanza deh J. Southern extension of the range of human babesiosis in the eastern United States. J Clin Microbiol 1999;37(6):2051-2.

[2] Conrad PA, Kjemtrup AM, Carreno RA, Thomford J, Wainwright K, Eberhard M, et al. Description of Babesia duncani n.sp. (Apicomplexa: Babesiidae) from humans and its differentiation from other piroplasms. Int J Parasitol 2006;36(7):779-89.

[3] Herwaldt BL, Cacciò S, Gherlinzoni F, Aspöck H, Slemenda SB, Piccaluga P, et al. Molecular characterization of a non-Babesia divergens organism causing zoonotic babesiosis in Europe. Emerg Infect Dis 2003;9(8):942-8.

[4] Hunfeld KP, Hildebrandt A, Gray JS. Babesiosis: recent insights into an ancient disease. Int J Parasitol 2008;38(11):1219-37.

[5] Kim JY, Cho SH, Joo HN, Tsuji M, Cho SR, Park IJ, Chung GT et al. First case of human babesiosis in Korea: detection and characterization of a novel type of Babesia sp. (KO1) similar to ovine Babesia. J Clin Microbiol 2007;45(6):2084-7.

[6] Gray JS, We iss LM. Babesia microti, in: Khan NA (Ed.), Emerging Protozoan Pathogens, Taylor and Francis, Abingdon, UK, 2008, pp. 303-349. 
[7] Hatcher JC, Greenberg PD, Antique J, Jimenez-Lucho VE. Severe babesios is in long Island: Review of 34 cases and their complications. Clin Infect Dis 2001;32(8):1117-25.

[8] Herwaldt BL, McGovern PC, Gerwel MP, Easton RM, MacGregor RR. Endemic babesiosis in another eastern state: New Jersey. Emerg Infect Dis 2003;9(2):184-8.

[9] Hildebrandt A, Gray JS, Hunfeld KP. Human babesiosis in Europe: what clinicians need to know. Infection 2013;41(6):1057-72.

[10] Gabrielli S, Calderini P, Cassini R, Galuppi R, Tampieri MP, Pietrobelli M, Cancrini G. Human exposure to piroplasms in Central and Northern Italy. Vet Ital 2014;50(1):41-7.

[11] Wei Q, Tsuji M, Zamoto A, Kohsaki M, Matsui T, Shiota T, et al. Human babesios is in Japan: isolation of Babesia microti-like parasites from an asymptomatic transfusion donor and from a rodent from an area where babesios is is endemic. J Clin Microbiol 2001;39(6):2178-83.

[12] Zhou X, Li SG, Chen SB, Wang JZ, Xu B, Zhou HJ, et al. Co-infections with Babesia microti and Plasmodium parasites along the China-Myanmar border. Infect Dis Poverty 2013;2(1):24.

[13] Paparini A, Senanayake SN, Ryan UM, Irwin PJ. Molecular confirmation of the first autochthonous case of human babesiosis in Australia using a novel primer set for the beta-tubulin gene. Exp Parasitol 2014;141:93-7. 
[14] Esch KJ, Petersen CA. Transmission and epidemiology of zoonotic protozoal diseases of companion animals. Clin Microbiol Rev 2013;26(1):58-85.

[15] Leiby DA. Babesiosis and blood transfusion: flying under the radar. Vox Sang 2006;90(3):157-65.

[16] Leiby DA. Transfusion-transmitted Babesia spp.: bull's-eye on Babesia microti. Clin Microbiol Rev 2011;24(1):14-28.

[17] Sethi S, Alcid D, Kesarwala H, Tolan RW Jr. Probable congenital babesios is in infant, new jersey, USA. Emerg Infect Dis 2009;15(5):788-91.

[18] Bock R, Jackson L, de Vos A, Jorgensen W. Babesiosis of cattle. Parasitol 2004;129Suppl:S247-69.

[19] Kjemtrup AM, Conrad PA. Human babesiosis: an emerging tick-borne disease. Int J Parasitol 2000;30(12-13):1323-37.

[20] Rodgers SE, Mather TN. Human Babesia microti incidence and Ixodes scapularis distribution, Rhode Island, 1998-2004. Emerg Infect Dis 2007;13(4):633-5.

[21] Aliota MT, Dupuis AP2nd, Wilczek MP, Peters RJ, Ostfeld RS, Kramer LD. The prevalence of zoonotic tick-borne pathogens in Ixodes scapularis collected in the Hudson Valley, New York State. Vector Borne Zoonotic Dis 2014;14(4):245-50. 
[22] Eshoo MW, Crowder CD, Carolan HE, Rounds MA, Ecker DJ, Haag H, Mothes B, Nolte O. Broad-range survey of tick-borne pathogens in Southern Germany reveals a high prevalence of Babesia microti and a diversity of other tick-borne pathogens. Vector Borne Zoonotic Dis 2014;14(8):584-91.

[23] Alekseev AN, Semenov AV, Dubinina HV. Evidence of Babesia microti infection in multi-infected Ixodes persulcatus ticks in Russia. Exp Appl Acarol 2003;29(3-4):34553.

[24] Zamoto-Niikura A, Tsuji M, Qiang W, Nakao M, Hirata H, Ishihara C. Detection of two zoonotic Babesia microti lineages, the Hobetsu and U.S. lineages, in two sympatric tick species, Ixodes ovatus and Ixodes persulcatus, respectively, in Japan. Appl Environ Microbiol 2012;78(9):3424-30.

[25] Saito-Ito A, Yano Y, Dantrakool A, Hashimoto T, Takada N. Survey of rodents and ticks in human babesiosis emergence area in Japan: first detection of Babesia microti-like parasites in Ixodes ovatus. J Clin Microbiol 2004;42(5):2268-70.

[26] Nakajima R, Tsuji M, Oda K, Zamoto-Niikura A, Wei Q, Kawabuchi-kurata T, et al. Babesia microti-group parasites compared phylogenetically by complete sequencing of the CCTy gene in 36 isolates. J Vet Med Sci 2009;71(1):55-68.

[27] Zamoto A, Tsuji M, Wei Q, Cho SH, Shin EH, Kim TS, et al. Epizootiologic survey for Babesia microti among small wild mammals in Northeastern Eurasia and a geographic diversity in the $ß$-tubulin gene sequences. J Vet Med Sci 2004;66(7):785-92. 
[28] Cornillot E, Hadj-Kaddour K, Dassouli A, Noel B, Ranwez V, Vacherie B, et al. Sequencing of the smallest apicomplexan genome from the human pathogen Babesia microti. Nucleic Acids Res 2012;40(18):9102-14.

[29] Cornillot E, Dassouli A, Garg A, Pachikara N, Randazzo S, Depoix D, et al. Whole genome mapping and re-organization of the nuclear and mitochondrial genomes of Babesia microti isolates. PLoS One 2013;8(9):e72657.

[30] Garg A, Stein A, Zhao W, Dwivedi A, Frutos R, Cornillot E, Ben Mamoun C. Sequence and annotation of the apicoplast genome of the human pathogen Babesia microti. PLoS One 2014;9(10):e107939.

[31] Hikosaka K, Watanabe Y, Tsuji N, Kita K, Kishine H, Arisue N, et al. Divergence of the mitochondrial genome structure in the apicomplexan parasites, Babesia and Theileria. Mol Biol Evol 2010;27(5):1107-16.

[32] Hikosaka K, Tsuji N, Watanabe Y, Kishine H, Horii T, Igarashi I, et al. Novel type of linear mitochondrial genomes with dual flip-flop inversion system in apicomplexan parasites, Babesia microti and Babesia rodhaini. BMC Genomics 2012;13:622.

[33] Oborník M, Janouskovec J, Chrudimský T, Lukes J. Evolution of the apicoplast and its hosts: from heterotrophy to autotrophy and back again. Int J Parasitol 2009;39(1):1-12. 
[34] Saxena V, Garg S, Ranjan S, Kochar D, Ranjan A, Das A. Analys is of elongation factor Tu (tuf A) of apicoplast from Indian Plasmodium vivax isolates. Infect Genet Evol 2007;7(5):618-26.

[35] Sivakumar T, Altangerel K, Battsetseg B, Battur B, Aboulaila M, Munkhjargal T, et al. Genetic detection of Babesia bigemina from Mongolian cattle using apical membrane antigen-1 gene based PCR assay. Vet Parasitol 2012;187(1-2):17-22.

[36] Battsetseg B, Xuan X, Ikadai H, Bautista JL, Byambaa B, Boldbaatar D, et al. Detection of Babesia caballi and Babesia equi in Dermacentor nuttalli adult ticks. Int J Parasitol 2001;31(4):384-6.

[37] Altangerel K, Sivakumar T, Battsetseg B, Battur B, Ueno A, Igarashi I, Yokoyama N. Phylogenetic relationships of Mongolian Babesia bovis isolates based on the merozoite surface antigen (MSA)-1, MSA-2b, and MSA-2c genes. Vet Parasitol 2012;184(24):309-16.

[38] Hong SH, Anu D, Jeong YI, Abmed D, Cho SH, Lee WJ, Lee SE. Molecular detection and seroprevalence of Babesia microti among stock farmers in Khutul city, Selenge province, Mongolia. Korean J Parasitol 2014;52(4):443-7.

[39] Arthur DR. Ticks: a monograph of the ixodoidea. Pt V Cambridge University Press London: 1960. p. 142-6. 
[40] Filippova NA. Ixodid tick of the subfamily Ixodinae. Fauna SSSR, Arachnoidea, 4(4). Lzd Nauka Leningrad (in Russian): 1977. p 316-30.

[41] Persing DH, Mathiesen D, Marshall WF, Teflford SR, Spielman A, Thomford JW, Conrad PA. Detection of Babesia microti by polymerase chain reaction. J Clin Microbiol 1992;30(8):2097-103.

[42] Kawabuchi T, Tsuji M, Sado A, Matoba Y, Asakawa M, Ishihara C. Babesia microti-like parasites detected in feral racoons (Procyon lotor) captured in Hokkaido, Japan. J Vet Med Sci 2005;67(8):825-7.

[43] Sivakumar T, Tattiyapong M, Okubo K, Suganuma K, Hayashida K, Igarashi I, et al. PCR detection of Babesia ovata from questing ticks in Japan. Ticks Tick borne Dis 2014;5(3):305-10.

[44] Campanella JJ, Bitincka L, Smalley J. MatGAT: an application that generates similarity/identity matrices using protein or DNA sequences. BMC Bioinformatics 2003;4:29.

[45] Tamura K, Stecher G, Peterson D, Filipski A, Kumar S. MEGA6: Molecular evolutionary genetics analysis version 6.0. Mol Biol Evol 2013;30(12):2725-9.

[46] Tamura K. Estimation of the number of nucleotide substitutions when there are strong transition-transversion and G + C-contents biases. Mol Biol Evol 1992;9(4):678-87. 
[47] Nei M, Kumar S. Molecular Evolution and Phylogenetics. Oxford Univeristy Press, New York: 2000.

[48] Holler JG, Röser D, Nielsen HV, Eickhardt S, Chen M, Lester A, et al. A case of human babesiosis in Denmark. Travel Med Infect Dis 2013;11(5):324-8.

[49] Poisnel E, Ebbo M, Berda-Haddad Y, Faucher B, Bernit E, Carcy B, et al. Babesia microti: an unusual travel-related disease. BMC Infect Dis 2013;13:99.

[50] Dash M, Byambaa B, Neronov VM. The ixodid tick fauna of the Mongolian People's Republic. I. The species distribution. Med Parazitol (Mosk) 1988;(3), 37-42.

[51] Sun Y, Liu G, Yang L, Xu R, Cao W. Babesia microti-like rodent parasites isolated from Ixodes persulcatus (Acari: Ixodidae) in Heilongjiang Province, China. Vet Parasitol 2008;156(3-4):333-9.

[52] Schnittger L, Rodriguez AE, Florin-Christensen M, Morrison DA. Babesia: a world emerging. Infect Genet Evol 2012;12(8):1788-809.

[53] Zahler M, Rinder H, Gothe R. Genotypic status of Babesia microti within the piroplasms. Parasitol Res 2000;86(8):642-6.

[54] Gou H, Guan G, Liu A, Ma M, Chen Z, Liu Z, et al. Coevolutionary analyses of the relationships between piroplasmids and the ir hard tick hosts. Ecol Evol 2013;3(9):298593. 
[55] Janouškovec J, Horák A, Oborník M, Lukeš J, Keeling PJ. A common red algal origin of the apicomplexan, dinoflagellate, and heterokont plastids. Proc Natl Acad Sci USA 2010;107(24):10949-54.

[56] Wan QH, Wu H, Fujihara T, Fang SG. Which genetic marker for which conservation genetics issue? Electrophoresis 2004;25(14):2165-76. 


\section{Figure legends}

Fig. 1. A phylogenetic tree of the $18 S$ rRNA sequences. The Mongolian B. microti sequences are shown in boldface letters. Bootstrap values are provided at the beginning of each branch. Note that all of the Mongolian sequences fall within the US-type.

Fig. 2. A phylogenetic tree of the cox1 sequences. The Mongolian B. microti sequences are shown in boldface letters. Bootstrap values are provided at the beginning of each branch. Note that the Mongolian sequences clustered together and formed a sister-clade to the R1 stra in sequences. 


\section{Graphical Abstract}

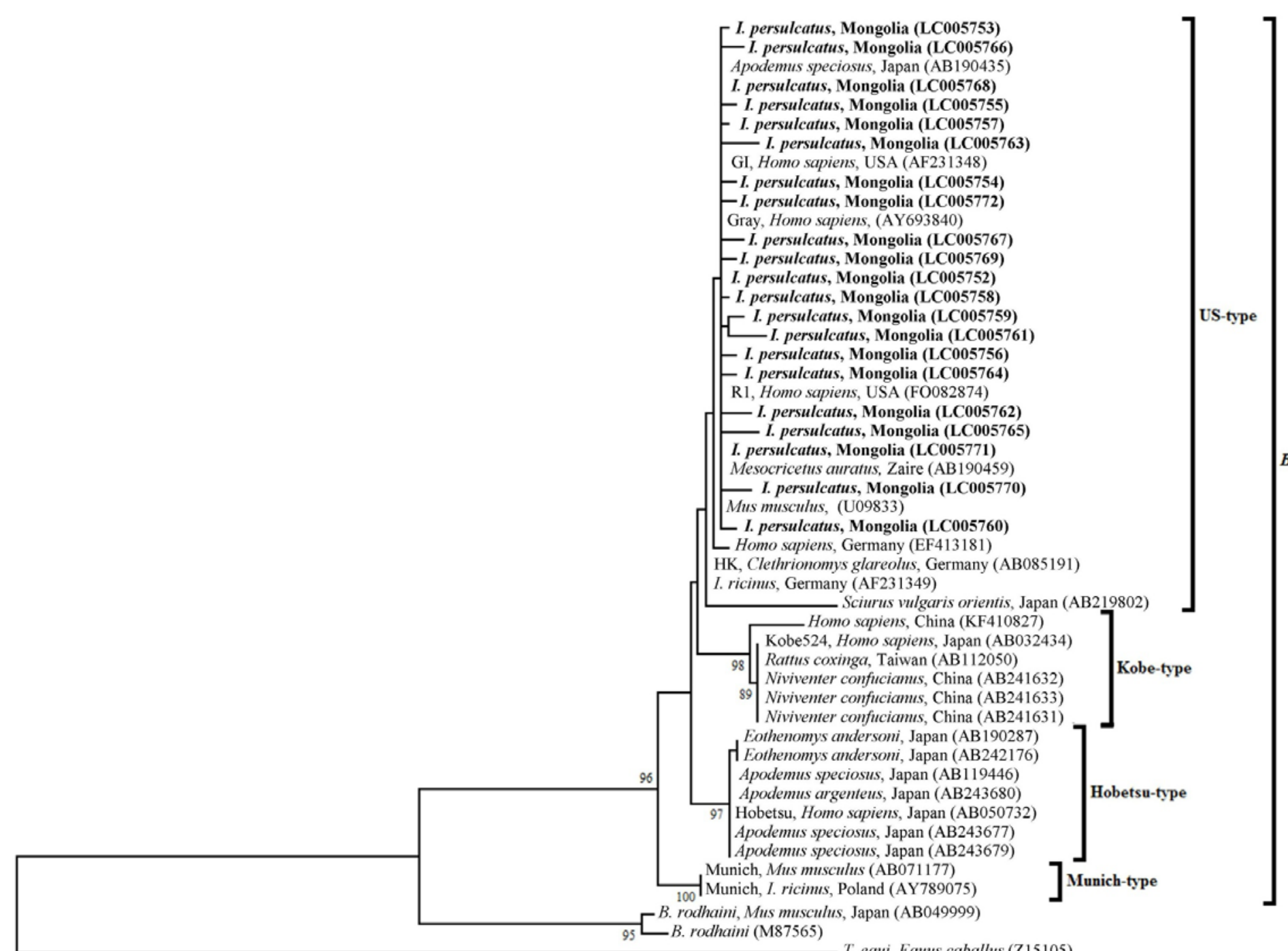


I. persulcatus, Mongolia (LC005753)

- I. persulcatus, Mongolia (LC005766)

Apodemus speciosus, Japan (AB190435)

I. persulcatus, Mongolia (LC005768)

- I. persulcatus, Mongolia (LC005755)

I. persulcatus, Mongolia (LC005757)

I. persulcatus, Mongolia (LC005763)

GI, Homo sapiens, USA (AF231348)

-I. persulcatus, Mongolia (LC005754)

- I. persulcatus, Mongolia (LC005772)

Gray, Homo sapiens, (AY693840)

- I. persulcatus, Mongolia (LC005767)

I. persulcatus, Mongolia (LC005769)

I. persulcatus, Mongolia (LC005752)

- I. persulcatus, Mongolia (LC005758)

- I. persulcatus, Mongolia (LC005759)

I. persulcatus, Mongolia (LC005761)

- I. persulcatus, Mongolia (LC005756)

- I. persulcatus, Mongolia (LC005764)

R1, Homo sapiens, USA (FO082874)

I. persulcatus, Mongolia (LC005762)

I. persulcatus, Mongolia (LC005765)

I. persulcatus, Mongolia (LC005771)

Mesocricetus auratus, Zaire (AB190459)

- I. persulcatus, Mongolia (LC005770)

Mus musculus, (U09833)

— I. persulcatus, Mongolia (LC005760)

- Homo sapiens, Germany (EF413181)

$\mathrm{HK}$, Clethrionomys glareolus, Germany (AB085191)

I. ricinus, Germany (AF231349)

Sciurus vulgaris orientis, Japan (AB219802)

Homo sapiens, China (KF410827)

Kobe524, Homo sapiens, Japan (AB032434)

98 Rattus coxinga, Taiwan (AB112050)

Niviventer confuciamus, China (AB241632)

89 Niviventer confuciamis, China (AB241633)

Niviventer confuciamis, China (AB241631)

Eothenomys andersoni, Japan (AB190287)

Eothenomys andersoni, Japan (AB242176)

Apodemus speciosus, Japan (AB119446)

Apodemus argenteus, Japan (AB243680)

97 Hobetsu, Homo sapiens, Japan (AB050732)

Apodemus speciosus, Japan (AB243677)

Apodemus speciosus, Japan (AB243679)

Munich, Mus musculus (AB071177)

100 Munich, I. ricimus, Poland (AY789075)

B. rodhaini, Mus musculus, Japan (AB049999)

$95-B$. rodhaini (M87565) 
I. persulcatus, Mongolia (LC005788) I. persulcatus, Mongolia (LC005813)

I. persulcatus, Mongolia (LC005789)

I. persulcatus, Mongolia (LC005801)

I. persulcatus, Mongolia (LC005812)

I. persulcatus, Mongolia (LC005787)

I. persulcatus, Mongolia (LC005786)

persulcatus, Mongolia (LC005802)

I. persulcatus, Mongolia (LC005806)

persulcatus, Mongolia (LC005790)

I. persulcatus, Mongolia (LC005785)

persulcatus, Mongolia (LC005807)

persulcatus, Mongolia (LC005781)

persulcatus, Mongolia (LC005778)

persulcatus, Mongolia (LC005811)

i. persulcatus, Mongolia (LC005808)

i. persulcatus, Mongolia (LC005809)

I. persulcatus, Mongolia (LC005810)

I. persulcatus, Mongolia (LC005797)

I. persulcatus, Mongolia (LC005792)

I. persulcatus, Mongolia (LC005805)

I. persulcatus, Mongolia (LC005796)

I. persulcatus, Mongolia (LC005795)

I. persulcatus, Mongolia (LC005779)

I. persulcatus, Mongolia (LC005793)

I. persulcatus, Mongolia (LC005803)

I. persulcatus, Mongolia (LC005780)

I. persulcatus, Mongolia (LC005804)

100 - Persulcatus, Mongolia (LC005794)

I. persulcatus, Mongolia (LC005784)

I. persulcatus, Mongolia (LC005800)

I. persulcatus, Mongolia (LC005791)

I. persulcatus, Mongolia (LC005798)

I. persulcatus, Mongolia (LC005782)

i. persulcatus, Mongolia (LC005783)

I. persulcatus, Mongolia (LC005799)

100

R1, Homo sapiens, USA (FO082868)

100 R1, Homo sapiens, USA (NC018345)

Chr. type-IV, Munich, Mus musculus (AB624356)

Chr. type-III, Munich, Mus musculus (AB624355)

99

Chr. type-II, Munich, Mus musculus (AB624354)

100 Chr. type-I, Munich, Mus musculus (AB624353)

Munich, Mus musculus (NC019570)

B. rodhaini, Chr. type -I, Mus musculus, Australian (AB624357)

B. rodhaimi, Chr. type -Il, Mus musculus, Australian (AB624358)

1001 B. rodhaini, Chr. type-IV, Mus mysculus, Australian (AB624360)

100

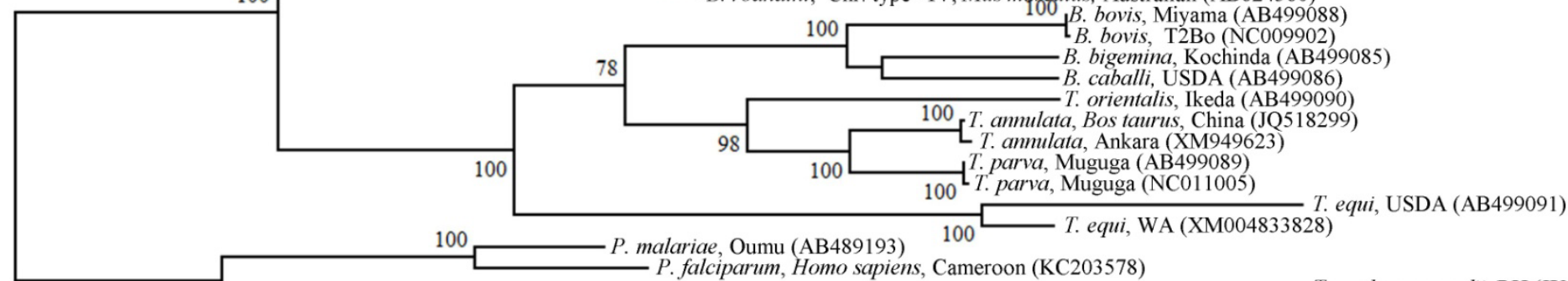

oxoplasma gondii, RH (JX473253)

E. tenella, NIAH, Gallus gallus domesticus (AB564272)

Fig. 2 
Table 1. PCR primers.

\begin{tabular}{|c|c|c|c|c|c|}
\hline Primers & Target genes & Sequences (5' - 3') & $\begin{array}{l}\text { Amplicon } \\
\text { sizes (bp) }\end{array}$ & $\begin{array}{l}\text { Annealing } \\
\text { temperatures }\end{array}$ & References \\
\hline $\begin{array}{l}\text { Bab1 } \\
\text { Bab4 } \\
\text { Bab2 } \\
\text { Bab3 }\end{array}$ & 18S rRNA & $\begin{array}{l}\text { CTTAGTATAAGCTTTTATACAGC } \\
\text { ATAGGTCAGAAACTTGAATGATACA } \\
\text { GTTATAGTTTATTTGATGTTCGTTT } \\
\text { AAGCCATGCGATTCGCTAAT }\end{array}$ & $\begin{array}{l}238 \\
154\end{array}$ & 54 & [40] \\
\hline $\begin{array}{l}\text { Piro0F2 } \\
\text { Piro6R2 } \\
\text { Piro1F2 } \\
\text { Piro5R2 }\end{array}$ & $18 S$ rRNA & $\begin{array}{l}\text { GCCAGTAGTCATATGCTTGTCTTA } \\
\text { CTCCTTCCTTTAAGTGATAAGGTTCAC } \\
\text { CCATGCATGTCTTAGTATAAGCTTTTA } \\
\text { CCTTTAAGTGATAAGGTTCACAAAACTT }\end{array}$ & $\sim 1702$ & 61 & [41] \\
\hline $\begin{array}{l}\text { Cox1F133 } \\
\text { Cox1R1130 }\end{array}$ & $\operatorname{cox} 1$ & $\begin{array}{l}\text { GGAGAGCTAGGTAGTAGTGGAGATAGG } \\
\text { GTGGAAGTGAGCTACCACAT ACGCTG }\end{array}$ & 1023 & 56 & This study \\
\hline $\begin{array}{l}\text { EFtuAF2 } \\
\text { EFtuAR2 }\end{array}$ & tufA & $\begin{array}{l}\text { ATGATAGTAGGTGTAACTCAAATGG } \\
\text { CACCTGGCATAGCCATTTTTAATTC }\end{array}$ & 823 & 55 & This study \\
\hline
\end{tabular}

